\title{
Research on Chemo-Mechanical-Grinding (CMG) of large size silica glass substrate
}

\author{
Takeshi SHIINA ${ }^{1}$, Libo ZHOU ${ }^{2}$, Zhongjun QIU ${ }^{3}$, Takeyuki YAMAMOTO ${ }^{4}$, Jun SHIMIZU ${ }^{5}$, Hiroshi EDA ${ }^{6}$ \\ ${ }^{1}$ Graduate School of Science and Engineering, Ibaraki University, 06nm922a@hcs.ibaraki.ac.jp \\ ${ }^{2}$ Department of Intelligent Systems Engineering, Ibaraki University, lbzhou@mx.ibaraki.ac.jp \\ ${ }^{3}$ VBL, Ibaraki University \\ ${ }^{4}$ Department of Intelligent Systems Engineering, Ibaraki University, ytake@mx.ibaraki.ac.jp \\ ${ }^{5}$ Department of Intelligent Systems Engineering, Ibaraki University, jshimizu@mx.ibaraki.ac.jp \\ ${ }^{6}$ Department of Intelligent Systems Engineering, Ibaraki University, eda@ipc.ibaraki.ac.jp
}

\begin{abstract}
:
As finishing techniques for silica glass substrate, the free abrasive processes are able to offer a better surface roughness, but sacrifice profile accuracy. On the other hand, the fixed abrasive process or grinding is known as a promising solution to improve accuracy of profile geometry, but always introduces damaged layer. In order to simultaneously achieve both surface quality and profile accuracy, this research has proposed a novel chemo-mechanical-grinding $(\mathrm{CMG})$ process by effective use of chemical reaction in the grinding process.
\end{abstract}

Keywords: Chemo-Mechanical-Grinding (CMG), Silica glass, Fixed abrasive process, Finishing technique

\section{Introduction}

As demand in highly accurate photomask goes up every year, demand for machining accuracy of silica glass substrate increases. It is because surface quality and profile accuracy of photomask influence optical characteristic as transmittance and aberration.

As finishing techniques for silica glass substrate, the free abrasive processes like lapping and polishing are able to offer a better surface roughness when finer abrasive are applied, but sacrifice profile accuracy. On the other hand, the fixed abrasive processes like grinding is known as a promising solution to improve accuracy of profile geometry, but always introduces damaged layer on the surface. In order to simultaneously achieve both surfaces quality and geometry accuracy, authors has developed CMG (Chemo-Mechanical-Grinding) process by effective use of chemical reaction in the grinding process.

This research aims to applying CMG to machining of silica glass substrate, and optimizing the machining conditions that simultaneously achieve surface quality, profile geometry and removal rate.

\section{Experimental methodology}

Figure 1 shows the grinding machine (NAGASE INTEGREX Co., LTD. KTC-1) used in this research for CMG processing of 6 inch silica glass substrate. The grinding machine incorporates two hydrostatic pressure spindles. The work spindle moves along Z-direction, and the wheel table oscillate along X-direction about $10 \mathrm{~mm}$.

Figure 2 shows two kinds of $\mathrm{CMG}$ wheels. Table 1 shows specification of CMG wheel. Type (a) uses the epoxy for bonding material, and wheel geometry is a ring shape. On the other hand, Type (b) uses the phenol for bonding material, and wheel geometry is radial shape.

In experiment on $\mathrm{CMG}, 6$ inch polished silica glass shown in Fig. 3 was ground until the pre-machined surface was completely removed. After grinding, surface roughness, permeability and removal rate were evaluated.

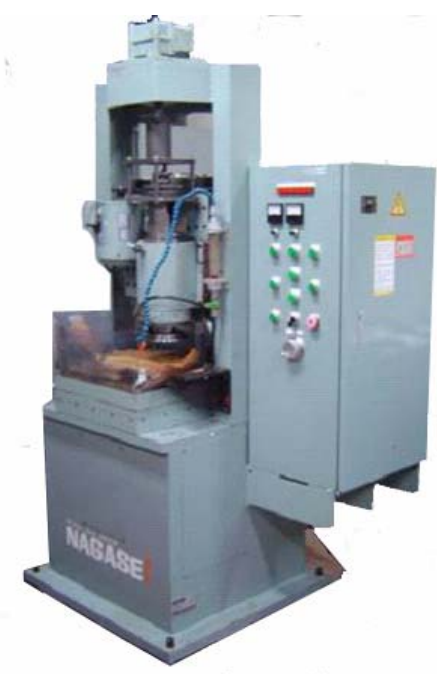

Figure 1: Grinding machine

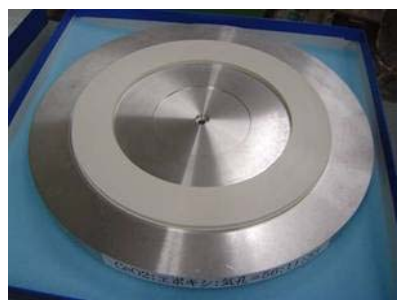

(a) Epoxy

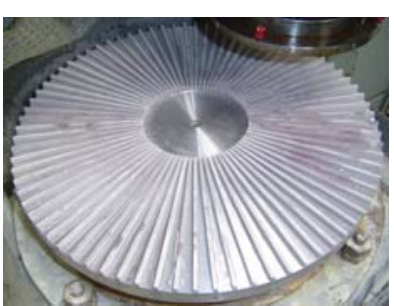

(b) Phenol
Figure 2: CMG wheels

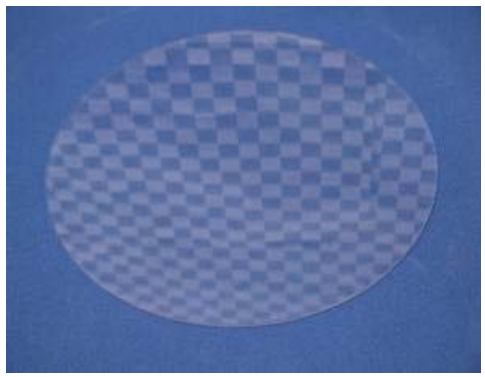

Figure 3: 6 inch silica glass wafer 
Moreover, these results are compared with commercial polished silica glass, and diamond ground silica glass as well.

\section{Result of the experiment}

\subsection{Evaluation of surface quality and aberration}

Both sides of 6 inch silica glass are machined by CMG, and surface roughness and permeability were evaluated. Experimental conditions are shown in Table 2. Machining time of one side varied from 20 to $50 \mathrm{~min}$. All surfaces of ground silica glasses are mirror finished.

In Fig. 4, (a), (b), and (c) shows the AFM image of machined surface by polishing, $\mathrm{CMG}$ and grinding by SD800 diamond wheel respectively. (b) shows a smooth surface almost similar to (a). On the other hand, a clear asperity can be confirmed on the surface of (c). Moreover, surface roughness of CMG is $0.46 \mathrm{~nm}$ Ra, which is better than that of (a). From these results, it is understood that surface quality of silica glass with $\mathrm{CMG}$ is obtained equally or better than that with polishing.

Results of the transmittance and reflectance of machined silica glass is shown in Fig. 5. Lines of CMG and polishing are almost overlapped, and the transmittance of $\mathrm{CMG}$ and polishing exceed $92 \%$ at visible range (wave length from $400 \mathrm{~nm}$ to $700 \mathrm{~nm}$ ).

From above results, it is able to conclude that both surface quality and transmittance of silica glass machined with $\mathrm{CMG}$ are equally or better than those with polishing.

\subsection{Optimization of machining conditions}

At the beginning of experiment, the removal rate was low though good results had been obtained for surface quality and permeability. Therefore, in order to improve removal rate, the experiment for optimization of machining conditions is performed by using quality engineering.

Table 3 shows the orthogonal array of $\mathrm{L}_{4}$ used in this experiment. The orthogonal array of $\mathrm{L}_{4}$ has three two-level factors, and correspondence with machining conditions is shown in Table 4.

According to four kinds of machining conditions shown in this orthogonal table, machining experiments are carried out in 30 minutes respectively, and removal rate and Ra are measured every 10 minutes. Dressing had been done only before machining in each conditions. Mist-coolant is used at $\mathrm{C} 1(0.1 \ell / \mathrm{min})$, and normal coolant is supplied at $\mathrm{C} 2(1.0 \ell / \mathrm{min})$.

Removal rate is calculated by Eq. (1) from mass reduction before and after CMG which is measured by an electronic balance.

$$
\begin{gathered}
\text { Removal Rate } \Delta h=\frac{4 \times \Delta M \times 10^{6}}{t \times \pi \times d^{2} \times \rho}(\mathrm{nm} / \mathrm{min}) \\
\begin{cases}\Delta M & : \text { Mass difference }(\mathrm{g}) \\
t & : \text { Processing time }(\mathrm{min}) \\
d & : \text { Diameter of workpiece }(\mathrm{mm}) \\
\rho & : \text { Density of workpiece }\left(\mathrm{g} / \mathrm{cm}^{3}\right)\end{cases}
\end{gathered}
$$

Table 1: Wheel specifications

\begin{tabular}{l|l|l}
\hline & (a) & (b) \\
\hline Abrasive & $\mathrm{CeO}_{2}$ & $\mathrm{CeO}_{2}$ \\
\hline Bonding agent & Epoxy & Phenol \\
\hline Additive & none & $\mathrm{Na}_{2} \mathrm{CO}_{3}$ \\
\hline Concentration of $\mathrm{CeO}_{2}$ & $56 \mathrm{vol} \%$ & $40 \mathrm{vol} \%$ \\
\hline Concentration of bonding agent & $11 \mathrm{vol} \%$ & $45 \mathrm{vol} \%$ \\
\hline Concentration of additive & - & $15 \mathrm{vol} \%$ \\
\hline Concentration of porousness & $33 \mathrm{vol} \%$ & - \\
\hline
\end{tabular}

Table 2: Experimental conditions

\begin{tabular}{l|l}
\hline Processing pressure & $12 \mathrm{kPa}$ \\
\hline Wheel revolution & $300 \mathrm{rpm}$ \\
\hline Work revolution & $50 \mathrm{rpm}$ \\
\hline Grinding fluid & $\begin{array}{l}\text { aqueous sodium hydroxide } \\
(\mathrm{pH}: 8.5), 0.6 \ell / \mathrm{min}\end{array}$ \\
\hline
\end{tabular}

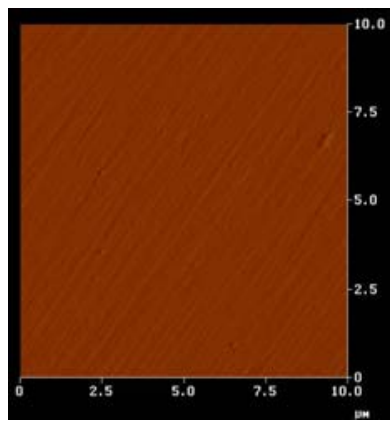

(a) Polishing

$(\mathrm{Ra}=0.56 \mathrm{~nm})$

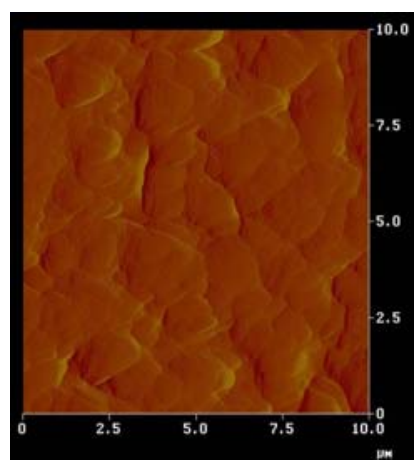

(c) Grinding by SD800

$(\mathrm{Ra}=72.9 \mathrm{~nm})$

Figure 4: AFM images

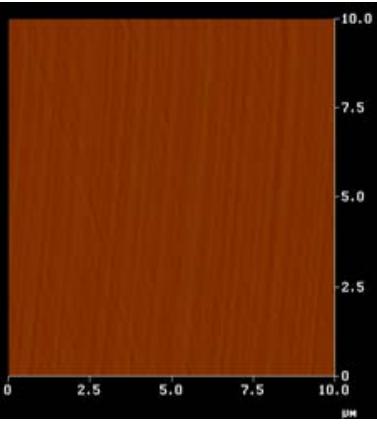

(b) $\mathrm{CMG}$

$(\mathrm{Ra}=0.46 \mathrm{~nm})$ 
Surface roughness and three dimensional topography were measured with NewView200 interferometer made by Zygo Company. Fig. 6 shows removal rate measured at each machining interval. Condition No.1 shows remarkably high removal rate about $190 \mathrm{~nm} / \mathrm{min}$, compared with others. Fig. 7 shows Ra measured at each machining interval. In each condition, $\mathrm{Ra}$ are around $0.8 \mathrm{~nm}$, and varied very little. Condition No. 2 shows the minimum value of $\mathrm{Ra}=0.6 \mathrm{~nm}$.

$\mathrm{SN}$ ratio at each condition is derived from these responded results $\mathrm{y}_{\mathrm{i}}$, and calculated by Eq. (2)

$$
\mathrm{SN} \text { ratio } \eta=-10 \log \left(\frac{1}{n} \times \sum_{i=1}^{n}\left(\frac{1}{y_{i}}\right)^{2}\right)
$$

Higher SN ratio means better condition (higher removal rate) in this case. Table 5 shows calculation result of SN ratio for each condition. No.1 stands out as the optimum condition in among four tested conditions because it shows the maximum SN ratio. Table 6 shows result of effect of each factor from $\mathrm{SN}$ ratio. In this table, the level with a large numerical value shows optimum conditions for each factor. Therefore, optimum conditions of removal rate is combination of $\mathrm{A}: 1, \mathrm{~B}: 1$, and $\mathrm{C}: 1$, and it is corresponding to condition of No.1. Which means that condition of lower rotational speed, higher pressure, and lower flowing quantity is preferable to obtain a high removal rate.

Similarly, SN ratio and effect of factor about Ra show Table 7 and Table 8 . In this case, SN ratio is derived by Eq. (3) because lower Ra is better.

$$
\text { SN ratio } \eta=-10 \log \left(\frac{1}{n} \times \sum_{i=1}^{n} y_{i}^{2}\right)(\mathrm{db})
$$

Higher SN ratio means better condition, or lower $\mathrm{Ra}$ in this case. No.2 stands out as the optimum condition among four tested conditions because it shows the maximum SN ratio. The optimum conditions of $\mathrm{Ra}$ derived from effect of factor is combination of $\mathrm{A}: 1, \mathrm{~B}: 2$, and $\mathrm{C}: 2$, and it is corresponding to condition of No.2. Therefore, it is shown that condition of higher pressure, higher rotational speed, and higher flowing quantity is preferable to have a small Ra.

In Fig. 8, (a) and (b) show three dimensional

topography of machined surface with polishing and CMG respectively. This is the result after $30 \mathrm{~min}$ machining at the condition of No.2

\section{Conclusion}

This research aims at a highly accurate machining of silica glass by CMG process in order to ensure both high quality and high accuracy. CMG was applied to 6 inch silica glass in this study. The obtained surface quality, profile geometry and removal rate were evaluated. The obtained results are summarized below.

(1) The grinding experiment by use of CMG processing for 6 inch silica glass is conducted, and machined surface is mirror finished.

(2) Surface roughness of silica glass machined with

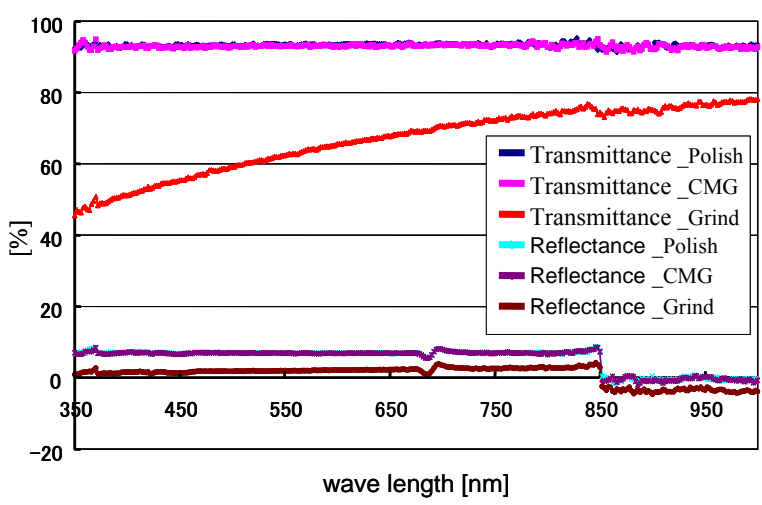

Figure 5: Transmittance and reflectance

Table 3: Orthogonal Table $\left(\mathrm{L}_{4}\right)$

\begin{tabular}{c|ccc}
\hline & 1 & 2 & 3 \\
No. & A & B & C \\
\hline 1 & 1 & 1 & 1 \\
2 & 1 & 2 & 2 \\
3 & 2 & 1 & 2 \\
4 & 2 & 2 & 1 \\
\hline
\end{tabular}

Table 4 Factor and level

\begin{tabular}{ll|cc}
\hline & Level & & \\
Factor & 1 & 2 \\
\hline A & Pressure $[\mathrm{kPa}]$ & 25 & 5 \\
$\mathrm{~B}$ & Wheel speed $[\mathrm{rpm}]$ & 100 & 500 \\
$\mathrm{C}$ & Coolant flow rate $[\ell / \mathrm{min}]$ & 0.1 & 1.0 \\
\hline
\end{tabular}

Table 5: SN ratio of removal rate

\begin{tabular}{c|ccc|c}
\hline No. & $\mathrm{y}_{1}$ & $\mathrm{y}_{2}$ & $\mathrm{y}_{3}$ & $\mathrm{~S} / \mathrm{N}[\mathrm{dB}]$ \\
\hline 1 & 191 & 121 & 83 & 41 \\
2 & 30 & 29 & 19 & 28 \\
3 & 10 & 9 & 5 & 17 \\
4 & 14 & 4 & 7 & 16 \\
\hline
\end{tabular}

Table 6: Effect of factor on removal rate

\begin{tabular}{c|ccc}
\hline Level & A & B & C \\
\hline 1 & 9 & 4 & 3 \\
2 & -9 & -4 & -3 \\
\hline
\end{tabular}


Table 7: SN ratio of $\mathrm{Ra}$

\begin{tabular}{c|ccc|c}
\hline No. & $\mathrm{y}_{1}$ & $\mathrm{y}_{2}$ & $\mathrm{y}_{3}$ & $\mathrm{~S} / \mathrm{N}[\mathrm{dB}]$ \\
\hline 1 & 1.20 & 0.79 & 0.78 & 0 \\
2 & 0.87 & 0.63 & 0.60 & 3 \\
3 & 0.79 & 0.83 & 0.78 & 2 \\
4 & 0.86 & 0.80 & 1.01 & 1 \\
\hline
\end{tabular}

Table 8: Effect of factor on Ra

\begin{tabular}{c|ccc}
\hline Level & A & B & C \\
\hline 1 & 0.1 & -0.4 & -0.9 \\
2 & -0.1 & 0.4 & 0.9 \\
\hline
\end{tabular}

CMG is $0.46 \mathrm{~nm}$. It is equal or better than that with polishing.

(3) The transmittance of silica glass machined with CMG is $92 \%$ or more, and it is almost equal to that with polishing.

(4) Removal rate has been improved to about $0.2 \mu \mathrm{m} / \mathrm{min}$ by optimizing machining conditions, using the quality engineering. Moreover, it has been understood that machining pressure and flow rate of grinding fluid greatly influence removal rate.

\section{References}

[1] Zhou, L., etc al, Research on Chemo-Mechanical-Grinding (CMG) of $\mathrm{Si}$ wafer -2nd Report: Generation of defect free surface on 300 $\mathrm{mm} \mathrm{Si}$ wafer by fixed abrasive process -, 2005, Journal of Precision Engineering, Vol.71, No.4, pp.466-470 (in Japanese)

[2] Zhou, L., etc al, T., A novel fixed abrasive process: chemo-mechanical grinding technology, 2005, Int. J. Manufacturing Technology and Management, Vol. 7, Nos. 5/6, pp.441-454

[3] Web Site: http://www.fiberbit.net/user/masa2logawa/ (in Japanese).

[4] Web Site: http://www.ne.jp/asahi/qequick/study/ (in Japanese).

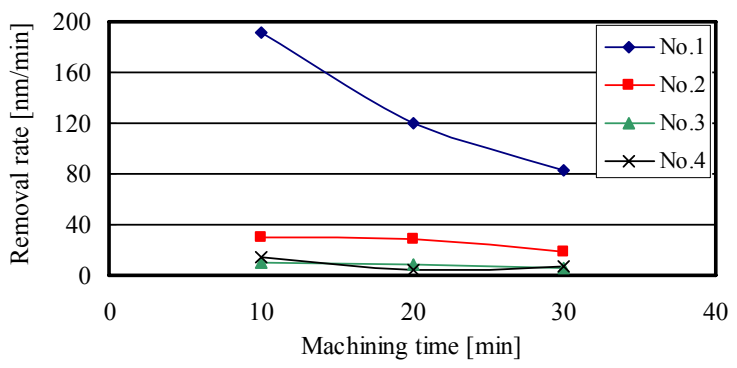

Figure 6: Removal rate

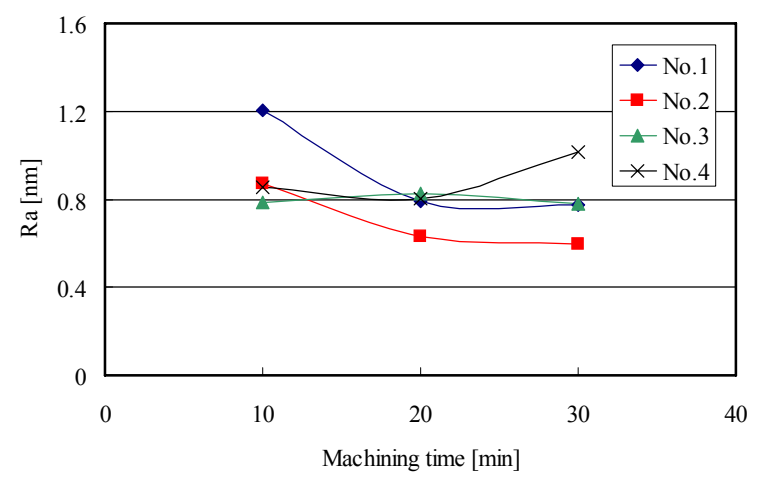

Figure 7: Surface roughness Ra

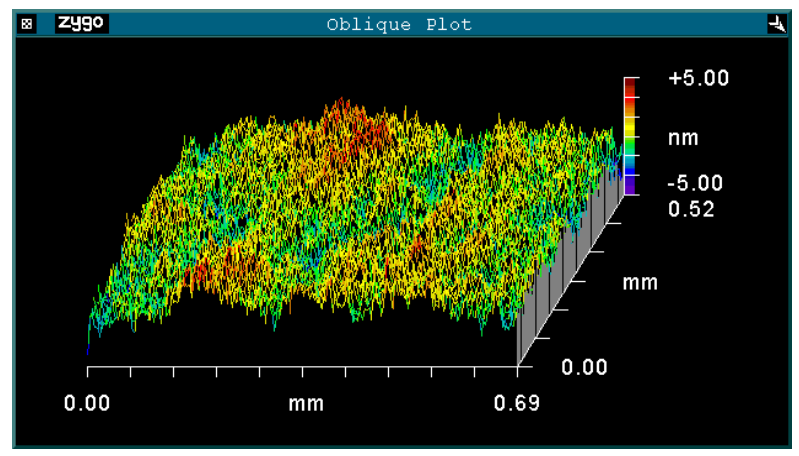

(a) Polishing $(\mathrm{Ra}=0.92 \mathrm{~nm})$

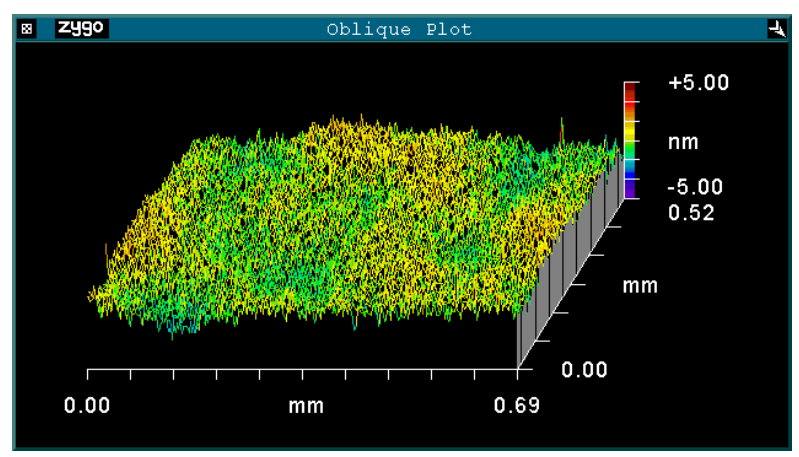

(b) $\mathrm{CMG}($ No.2, 30min) $(\mathrm{Ra}=0.60 \mathrm{~nm})$

Figure 8: 3D topography of silica glass 